\title{
Knowledge and attitude towards nursing profession among male secondary level students
}

Khatri $A^{1}$ iD , Singh $R^{2}$ iD

${ }^{1}$ Asmita Khatri, Nursing officer, Ministry of Social Development, Bagmati Province, Hetauda, Makwanpur, Nepal; ${ }^{2}$ Regina Singh, Professor, Department of Nursing, Kathmandu Medical College Teaching Hospital, Bhaktapur, Nepal.

\begin{abstract}
Background: Nursing profession is stereotyped worldwide. In Nepal, the enrollment of males in nursing education was initiated in 1986 AD with allocation of 10\% seats, which stopped after enrollment of four batches only. Nepal Nursing council has announced 15\% allocation of nursing seats to male students from academic year 2018/19 AD but only a few number of males have been enrolled.

Objectives: The aim of this study was to determine the knowledge and attitude towards the nursing profession among male secondary level students.

Methodology: A descriptive cross-sectional study was conducted by employing multi-stage sampling technique in June, 2019. Random list of secondary schools of Kathmandu district was created followed by proportionate stratified random sampling among $80 \%$ of male students studying in grades nine and ten from initial ten schools from the randomized list. The sample size was 388. A self-structured questionnaire was administered. Data was analyzed in SPSS version 20 by using frequency, percentage, mean, chi-square test and pearson's correlation coefficient.

Results: Out of 388 respondents, only $55.4 \%$ had adequate knowledge and only $53.4 \%$ had a more positive attitude towards the nursing profession. Significant association was found between knowledge towards the nursing profession with two of the socio-demographic variables grade of student and respondent's family, friends and relatives in the nursing profession.

Conclusion: The study showed inadequate knowledge and less positive attitude towards the nursing profession. Educational programs regarding different aspects of nursing profession should be planned timely by professional nursing organizations, nursing colleges and secondary schools of Nepal which would create a positive impact in enrollment of male nursing students in coming academic years.
\end{abstract}

Key words: Attitude; Knowledge; Nursing.

Access this article online

Website: www.jkmc.com.np

DOI: https://doi.org/10.3126/jkmc.v9i3.36412

HOW TO CITE

Khatri A, Singh R. Knowledge and attitude towards nursing profession among male secondary level students. J Kathmandu Med Coll. 2020;9(3):137-43.

\section{Address for correspondence}

Asmita Khatri

Ministry of Social Development

Bagmati Province, Hetauda, Makwanpur, Nepal

E-mail: asmitakhatri1996@gmail.com

Copyright @ 2020 Journal of Kathmandu Medical College (JKMC)

ISSN: 2019-1785 (Print), 2091-1793 (Online)

\section{INTRODUCTION}

The World Health Organization (WHO) defines I nursing as "Nursing encompasses autonomous and collaborative care of individuals of all ages, families, groups and communities, sick or well and in all settings. It includes the promotion of health, the prevention of illness, and the care of ill, disabled and dying people"1.

Likewise, the definition of 'nursing' given by various authors and organizations focus only on functions and characteristics of a nurse. Gender division or genderspecific nursing roles has not been mentioned in literature, however, the nursing profession has been widely stereotyped worldwide from the time its concept came into existence till this date ${ }^{2,3}$.

In the history of nursing in the world, the earliest recorded detail of nurses is from India in $250 \mathrm{BC}$ with the opening 
of the first school of nursing predominantly for males as females were considered impure. By the Christian era (400 AD), nursing care was established as a genderspecific role where female nurses would care for women while overall patient care and hospital administration was handled by male nurses ${ }^{4,5}$. Till the sixteenth century, the provision of health services was the responsibility of male nurses until this field found Florence Nightingale. She firmly established nursing as a female occupation. After that, the family-based institutional model emerged in which the dominant role of father was assumed to be male physicians, nurses as mother and patients as children ${ }^{6}$. With the increasing number of male nurses in the west, the attitude, perception, advantages, outcome and challenges of male nurses have been explored to some extent.

Formal nursing education started in Nepal in 1959 AD $^{7-9}$ with inclusion of females only. With the increasing need for nursing human resources, enrollment of males was initiated in nursing education in 1986 AD. A total of four batches of male nurses were enrolled, then, in $1990 \mathrm{AD}$ the enrollment of male nurses was terminated for two main reasons. First, the people were uncomfortable with male nurses and complained that they did not get the similar care from a male nurse as they would have from female nurses. Secondly, the graduated male nurses did not serve in the rural areas as they were supposed to. During this period, almost 80 male nurses were produced inside the country9,10.

Two decades after the termination of enrollment of male students in nursing education, a new era has started in Nepal since Nepal Nursing Council (NNC) announced to enroll male students in nursing programs of Nepal from academic year 2018/19 (July), allocating 15\% quota for males ${ }^{11-13}$. Nepal was the only country among 130 other member countries associated with the International Council for Nurses' (ICN) that did not allow males to study nursing, and the council pressed NNC for more gender equality. Also, after the devastating earthquake in $2015 \mathrm{AD}$, the need for male nurses was felt. Likewise, the people nowadays are literate, accepting and male nurses will be willing to work at rural government health centers too due to satisfactory wages, which stood as a major problem in the past ${ }^{13}$.

The Constitution of Nepal has not discriminated gender in terms of occupation. No occupation has been classified as gender-based. The occupations which were traditionally considered patriarchal like drivers, pilots, masons, etc. are not limited to males today. There are competent and well-established females in these professions. Likewise, the jobs like tailoring, janitors which were performed by females mostly are now performed equally by both genders ${ }^{14}$. No literature supports gender stereotyping in the nursing profession yet it persists in our context.

In our cultural society, nursing care is also linked with sensitivity. Male patients feel awkward when cared intimately by female nurses. They also complain of not being able to tell everything to a female nurse, being males. Certain nursing skills and care which are associated with privacy like inserting Foley's catheter, bowel and bladder care, obtaining sexual history, are awkward for the patients when being performed by young female nurses ${ }^{10}$.

There are more than 120 nursing colleges in Nepal (Proficiency Certificate Level and Bachelor of Science in Nursing). About 7740 nurses are produced annually in Nepa ${ }^{10}$. After the announcement of NNC to allocate $15 \%$ of nursing seats for male students from academic year 2018/19, about 1000 students should have been enrolled ${ }^{10,13,15}$. The exact data on the number of male students enrolled in the academic year 2018/19 is not available yet but it is heard that only a limited number of male students have been admitted to study nursing in the academic year 2018/19. The general public might not be aware of the inclusion of males in nursing education in Nepal. Also, the stereotyping of the nursing profession, the view of the public on nursing as not being a respected profession, comparison of nursing with other health care professions might be the reasons for this. The students of grades nine and ten are in the stage where they start to explore their career opportunities and they are also the potential candidates to study nursing. Hence, the objective of this study was to assess the knowledge and attitude of male students studying in grades nine and ten towards the nursing profession.

\section{METHODOLOGY}

A descriptive cross-sectional study was conducted in June, 2019 in randomly selected private as well as government schools of Kathmandu district since Kathmandu district has the highest number of secondary schools ${ }^{15}$. This study was conducted in male students only as nursing profession is a very popular and widely accepted career choice among females at present but for males, it is a relatively new career choice, especially in Nepalese society where stereotyping of nursing profession is widely prevalent.

Taking 50\% prevalence and 5\% margin of error, sample size was calculated as 384 for $95 \%$ confidence interval. 
A multi-stage sampling technique was used. Out of the 977 secondary schools of Kathmandu district ${ }^{15}$, a random list of the schools was created in Microsoft Excel sheet by using Computer generated sampling technique. From the randomized list of schools, initial ten schools were approached. The total number of male students in grades nine and ten of those schools was inquired. Then, a proportionate stratified random sampling method was employed to recruit participants from each school to meet the sample size (i.e. 384). From the total male population of grades nine and ten, $80 \%$ of students were recruited for the study respectively from each class and the final sample size became 388 on doing this. Only ten schools were approached for proportionate stratified random sampling due to limited time and resources. The sampling process is shown in a flow chart below:

Total no. of secondary schools in Kathmandu district

$$
\downarrow
$$

Random list of secondary schools was created in Microsoft excel using Computer generated sampling technique

$$
\downarrow
$$

Initial ten schools of the random list was approached

$$
\downarrow
$$

Total no. of male students in grades 9 and 10 of the schools was inquired (to estimate the proportion needed to be enrolled so as to meet the calculated

$$
\text { sample size) }
$$$$
\downarrow
$$

For each school, out of all male students in grade 9, 80\% were recruited for the study. The same was done for grade 10 .

$$
\downarrow
$$

The final sample size became 388 on doing this in all 10 schools

\section{Figure 1: Sampling process}

Ethical approval was obtained from the Institutional Review Committee (IRC) of Kathmandu Medical College (Ref: 3105201115). Written formal permission was obtained from the Principal of respective schools. Informed written consent was obtained from each participant. Anonymity and confidentiality of the respondents was maintained during as well as throughout the study.

A structured questionnaire was developed. Content validity of the questionnaire was checked by pre-testing it in one government and one non-government school of Lalitpur, extensive literature review and consulting with the research advisor. Necessary changes were made after pre-testing the tool. Knowledge dimension consisted of three parts and a total of 25 items. Mean knowledge score of respondents was calculated and knowledge score less than mean score was categorized as 'Inadequate knowledge' while knowledge score more than or equal to mean score was categorized as 'Adequate knowledge'. Attitude dimension consisted of 10 items and rated on three point rating scale. Mean attitude score of respondents was calculated and attitude score less than mean score was categorized as 'Less positive attitude' while attitude score more than or equal to mean score was categorized as 'More positive attitude'.

Data was collected in respective class rooms of respective schools through self-administered questionnaires. Collected data was analyzed by using SPSS (Statistical Package for the Social Sciences) version 20. Chi-square test was used to find the association of knowledge and attitude towards nursing profession with selected sociodemographic variables respectively while Pearson's correlation coefficient was used to find the relationship between knowledge and attitude towards nursing profession.

\section{RESULTS}

The mean age of the respondents was $15 \pm 1.13$ years $(n=388)$.

Majority of the students were from non-government schools and followed Hinduism.

Majority of the respondents (80.1\%) had correct knowledge regarding the fact that males can also study nursing in Nepal while knowledge regarding the entry criteria, scope of nursing profession and requirement of nurses was incorrect. The knowledge regarding entry criteria and nursing profession was more compared to knowledge regarding nurses' opportunities. The total knowledge score was adequate only in around half of the respondents (55.4\%).

Association was found between the grade of student and respondent's family, friends and relatives in the nursing profession with knowledge towards the nursing profession but not with type of school and religion.

Although $62.0 \%$ and $88.2 \%$ of the respondents agreed on nursing being a challenging and respected profession respectively, only $16.9 \%$ of them considered nursing for a career choice in future. More than half of the respondents $(65.3 \%)$ had positive attitudes regarding the gender of nurses. 
More than half of the respondents (53.4\%) had a more positive attitude towards the nursing profession while the rest (46.6\%) had a less positive attitude. There was no association of attitude towards the nursing profession with any socio-demographic variables.
A moderate positive correlation was found between knowledge and attitude towards the nursing profession ( $r=0.36$ at 0.01 level of significance).

Table 1: Distribution of respondents according to socio-demographic profile $(\mathbf{n}=\mathbf{3 8 8})$

\begin{tabular}{llc} 
S.N. Socio-demographic variables & Frequency & Percentage (\%) \\
Grade & & 43.3 \\
1. Nine & 168 & 56.7 \\
Ten & 220 & \\
Students belonging to different schools (Type of school) & 19.6 \\
2. Government & & 80.4 \\
Non-government & 76 & 75.5 \\
Religion & 312 & 19.3 \\
Hindu & & 3.4 \\
Buddhist & 293 & 1.8 \\
Christian & 75 & 13 \\
Others & 7 & 56.2 \\
Family, friends and relatives in nursing profession & & 43.8 \\
\hline
\end{tabular}

Table 2: Total knowledge score regarding nursing profession $(\mathbf{n}=\mathbf{3 8 8})$

\begin{tabular}{|lcc|}
\hline Areas of Knowledge dimension & Adequate (\%) & Inadequate (\%) \\
\hline Knowledge regarding entry criteria of nursing profession & $220(56.7)$ & $168(43.3)$ \\
\hline Knowledge regarding nursing profession & $223(57.5)$ & $165(42.5)$ \\
\hline Knowledge regarding nurses' opportunities & $174(44.8)$ & $214(55.2)$ \\
\hline Total Knowledge score & $215(55.4)$ & $173(44.6)$ \\
\hline
\end{tabular}

Table 3: Association between knowledge towards nursing profession and selected socio-demographic variables $(\mathbf{n}=388)$

\begin{tabular}{lcc} 
Socio-demographic variables & \multicolumn{2}{c}{ Knowledge score } \\
Inadequate & $\begin{array}{c}\text { Adequate (frequency/ } \\
\text { percentage) }\end{array}$ & (frequency/percentage) \\
Grade of student & $\mathbf{7 9 ( 2 0 . 4 \% )}$ & $\mathbf{8 9 ( 2 2 . 9 \% )}$ \\
Nine & $\mathbf{1 3 6 ( 3 5 . 0 \% )}$ & $\mathbf{8 4 ( 2 1 . 7 \% )}$ \\
Ten & & \\
Family, friends and relatives in nursing profession & $103(26.5 \%)$ & $67(17.3 \%)$ \\
Yes & $112(28.9 \%)$ & $106(27.3 \%)$ \\
No & & $\mathbf{0 . 0 0 4 *}$ \\
\hline
\end{tabular}

*p value significant at $\leq 0.05$ 
Table 4: Association between attitude towards nursing profession and selected demographic variables ( $\mathrm{n}=\mathbf{3 8 8}$ )

\begin{tabular}{|c|c|c|c|}
\hline \multirow[b]{2}{*}{ Socio-demographic variables } & \multicolumn{2}{|c|}{ Attitude score } & \multirow[b]{2}{*}{ p-value } \\
\hline & $\begin{array}{c}\text { More positive (frequency/ } \\
\text { percentage) }\end{array}$ & $\begin{array}{c}\text { Less positive (frequency/ } \\
\text { percentage) }\end{array}$ & \\
\hline \multicolumn{4}{|l|}{ Grade of student } \\
\hline Nine & $85(21.9 \%)$ & $83(21.4 \%)$ & \multirow{2}{*}{0.342} \\
\hline Ten & $122(31.4 \%)$ & $98(25.3 \%)$ & \\
\hline \multicolumn{4}{|l|}{ Type of school } \\
\hline Government & 35 (9.0\%) & $41(10.6 \%)$ & \multirow{2}{*}{0.155} \\
\hline Non-government & $172(44.3 \%)$ & $140(36.1 \%)$ & \\
\hline \multicolumn{4}{|l|}{ Religion } \\
\hline Hindu & $157(40.5 \%)$ & $136(35.0 \%)$ & \multirow{4}{*}{0.991} \\
\hline Buddhist & $35(9.0 \%)$ & $30(7.7 \%)$ & \\
\hline Christian & $8(2.1 \%)$ & $13(3.4 \%)$ & \\
\hline Others & $7(1.8 \%)$ & $2(0.5 \%)$ & \\
\hline \multicolumn{4}{|l|}{$\begin{array}{l}\text { Family, friends and relatives in } \\
\text { nursing profession }\end{array}$} \\
\hline nursing protession & $94(24.2 \%)$ & $76(19.6 \%)$ & \\
\hline $\begin{array}{l}\text { res } \\
\text { No }\end{array}$ & $113(29.1 \%)$ & $105(27.1 \%)$ & 0.385 \\
\hline
\end{tabular}

\section{DISCUSSION}

The findings of this study showed inadequate knowledge and less positive attitude towards the nursing profession. Educational level of students, inadequacy of measures to make secondary level male students aware of their career options, limited provisions of educational campaigns on knowledge regarding different aspects of nursing profession by nursing colleges and professional nursing organizations might be the reason for inadequate knowledge towards nursing profession. Gender stereotyping of nursing is highly prevalent in Nepalese society and inadequate knowledge regarding nursing profession might be the reason for less positive attitude towards nursing profession.

A similar study conducted in Pune, India, showed a reasonable score in knowledge dimension and less score on attitude dimension. The difference in knowledge score could be due to the difference in educational level since the study was conducted among adolescent students of junior colleges while this study was done among students of grades nine and ten. The similarity in attitude score might be due to the gender stereotyping of nursing profession in both contexts. Likewise, moderate correlation was found between knowledge and attitude in both studies ${ }^{16}$.

A study conducted in Cairo, found inaccurate knowledge regarding professional preparation of nurses and nurses' role which is similar to the findings of our study. Only $44.8 \%$ reported that nurses can have master or doctoral degrees while in our study $75.6 \%$ reported that nurses can pursue higher education (up to PhD). Regarding the attitude towards the nursing profession, the majority of respondents agreed that nursing is a respected profession and important profession for the society which is in line with findings of this study. It showed inaccurate knowledge and a negative attitude towards the nursing profession. This similarity in knowledge could be due to the similar educational level of respondents in both studies and the inaccurate knowledge could be the reason for negative attitudes. It also showed a strong positive correlation between respondents' knowledge and their attitude toward the nursing profession ${ }^{17}$.

A study conducted in Saudi Arabia showed good knowledge on the nursing profession as the respondents were pre-clinical students of a nursing college. Also, respondents acknowledged that nurses assist doctors in caring for patients, nursing involves caring for patients, nursing care is based on scientific knowledge, nurses are well educated and nurses need skill and knowledge to provide care which is in line with the findings of our study. However, only half of the respondents recognized that nurses educate patients about their illness whereas in this study majority of respondents recognized that nurses provide health education to patients. Regarding items of attitude, respondents believed that nursing is a challenging career which is in line with this study whereas they believed nursing jobs can be found wherever they go which is opposite to the findings from this study. In contrast to our study findings, the majority of participants disagreed that the nursing profession is a job for females only in which more than half of the 
respondents agreed that nursing is suited for females only ${ }^{18}$.

A study conducted in Oman found an overall positive attitude about the nursing profession. The study was conducted using convenient sampling techniques in both male and female college students and majority of respondents were from nursing faculty which might be the reason for an overall positive attitude contrasting with the findings of the study. No significant association between academic year and attitude towards the nursing profession which is in line with this study ${ }^{19}$.

After data collection from each class, the respondents were provided with information regarding nursing courses available in Nepal and their entry criteria, scope of nursing profession, roles and responsibilities of nurses, professional preparation of nurses, opportunities for nurses and the recent announcement by NNC to enroll males in nursing education in Nepal. An open discussion was held at the end to clear the respondents' doubts regarding different aspects of the nursing profession.

Considering the findings on knowledge and attitude towards nursing profession generated from this study, nursing colleges of Nepal can collaborate with the professional nursing organizations and nursing entrance preparation institutes to conduct educational campaigns related to different nursing courses available in Nepal, eligibility criteria for joining those courses, scope of nursing profession, roles and responsibilities of nurses, gender of nurses in secondary level schools of the country. This would aid in broadening the understanding of the nursing profession among the potential candidates to study nursing so that they can consider nursing as one

\section{REFERENCES}

1. WHO. Nursing. WHO [Internet]. 2019. [DOI]

2. Ten Hoeve $Y$, Jansen $G$, Roodbol P. The nursing profession: public image, self-concept and professional identity. A discussion paper. J Adv Nurs [Internet]. 2014 Feb 1;70(2):295-309. [PubMed | Full text| DOI]

3. Tackling gender stereotypes in nursing. Explorehealthcareers.org [Internet]. 2018 Nov 27. [DOI]

4. Christensen M. Men in nursing: The early years. J Nurs Educ Pract [Internet]. 2017;7(5):94. [DOI]

5. Harding T. Men in nursing - a brief history. Nurse Uncut [Internet]. 2012 Sep 18. [DOI] of the appropriate career choices they have. Professional nursing organizations can spread the knowledge regarding different aspects of nursing profession via social media, mass media and can also collaborate with the schools to provide the interested students with required information on nursing. The findings from this study can be used to form plans and policies to facilitate the males enrolled in nursing education at present and increase the enrollment of male students in coming academic years by addressing the issues recognized in this study.

Similar studies are recommended among male students of grades nine and ten in different parts of Nepal as well as among male students studying in grades 11 and 12 in Science stream.

\section{CONCLUSION}

The study showed inadequate knowledge and less positive attitude towards the nursing profession. Significant association was found between grade of students and respondent's family, friends and relatives in the nursing profession with Knowledge towards the nursing profession. A moderate positive correlation was found between Knowledge and Attitude towards the nursing profession.

\section{ACKNOWLEDGEMENT}

We would like to thank all the schools and the participant students for their time and positive response to the study.

\section{Conflict of interest: None} Source(s) of support: None

6. Arif S, Khokhar S. A historical glance: Challenges for male nurses. J Pak Med Assoc [Internet]. 2017 Dec;67(12):1889-1894. [PubMed]

7. Rai D. Growth of nursing education sector and its effects on professionalization of nurses in Nepal. IOSR-JNHS [Internet]. 2014 Jul-Aug;3(4). [Full text]

8. Prakash S, Yadav $\mathrm{P}$, Yadav K. Perspectives of developing nursing education in Nepal. Nursing \& Care Open Access Journal [Internet] 2018 Jul;5(4) [Full text]

9. Sigdel R. Nursing education in Nepal: Historical perspective. Heal Prospect [Internet]. 2011;10:89-90. [DOI]

10. Khanal K. Nepal's nursing colleges reserve spots for male students. Globalpress Journal [Internet]. 2019 Jan. [DOI] 
11. Nakarmi A. NNC has allocated $15 \%$ seats in nursing to male students. Nepal Buzz [Internet]. 2018 June 26. [DOI]

12. Paudel N. Council opens nursing courses to male students. The Kathmandu Post [Internet] 2018 Jun 6:General. [DOI]

13. Prasai B. Into the revival of male nursing in Nepal. The Annapurna Express [Internet] $2018 \mathrm{Jul}$ 14; [DOI]

14. Acharya S. Gender, jobs, and education : prospects and realities in Nepal [Internet]. UNESCO Office. Kathmandu [Internet]. 2015. 108 p. [DOI]

15. School-wise SEE symbol number. Kathmandu:District Education Committee. 2019. [DOI]

16. Shiroor G, Podder L, Manna M, Professor A, Professor A. Knowledge and attitude regarding nursing as a career among adolescence. Int J Multidiscip Res Dev [Internet]. 2017 Aug;4(8):90-2. [DOI]

17. Mohammed MK, Abdo LM. Identifying knowledge and attitude of secondary school students toward nursing profession in Cairo Governorate. Med. J. Cairo Univ [Internet].2015;83(1):443-7. [Full text]

18. Hatamleh W, Sorio EL. Knowledge, attitude and intention towards nursing profession among pre-clinical students. J Heal Spec [Internet]. 2017 Jan;5(3):135. [Full text | DOI]

19. Shukri RK, Bakkar BS, El-damen MA, Ahmed SM.Attitudes of students at Sultan Qaboos University towards the nursing profession. Sultan Qaboos Univ Med J [Internet]. 2013 Nov;13(4):539-44. [PubMed | Full text] 